\title{
Review
}

International Archives of
Allergy
Immunology

\section{Tryptophan Metabolism in Allergic Disorders}

\author{
Johanna M. Gostner ${ }^{a}$ Katrin Becker ${ }^{b}$ Heinz Kofler ${ }^{c}$ Barbara Strasser $^{a}$ \\ Dietmar Fuchs ${ }^{\text {b }}$
}

Divisions of a Medical Biochemistry and ${ }^{b}$ Biological Chemistry, Biocenter, Innsbruck Medical University, Innsbruck, and ${ }^{\mathrm{C}}$ Allergy Ambulance, Hall, Austria

\section{Key Words}

Allergy · Atopy $\cdot$ Indoleamine 2,3-dioxygenase-1 .

Interferon- $\gamma \cdot$ Kynurenine to tryptophan ratio $\cdot$ Neopterin .

Nitric oxide $\cdot$ Th2-type immunity $\cdot$ Tryptophan

\section{2,3-dioxygenase}

\begin{abstract}
Allergic diseases such as asthma and rhinitis, as well the early phase of atopic dermatitis, are characterized by a Th2skewed immune environment. Th2-type cytokines are upregulated in allergic inflammation, whereas there is downregulation of the Th1-type immune response and related cytokines, such as interferon- $\gamma$ (IFN- $\gamma)$. The latter is a strong inducer of indoleamine 2,3-dioxygenase-1 (IDO-1), which degrades the essential amino acid tryptophan, as part of an antiproliferative strategy of immunocompetent cells to halt the growth of infected and malignant cells, and also of T cells - an immunoregulatory intervention to avoid overactivation of the immune system. Raised serum tryptophan concentrations have been reported in patients with pollen allergy compared to healthy blood donors. Moreover, higher
\end{abstract}

baseline tryptophan concentrations have been associated with a poor response to specific immunotherapy. It has been shown that the increase in tryptophan concentrations in patients with pollen allergy only exists outside the pollen season, and not during the season. Interestingly, there is only a minor alteration of the kynurenine to tryptophan ratio (Kyn/ Trp, an index of tryptophan breakdown). The reason for the higher tryptophan concentrations in patients with pollen allergy outside the season remains a matter of discussion. To this regard, the specific interaction of nitric oxide (NO*) with the tryptophan-degrading enzyme IDO-1 could be important, because an enhanced formation of $\mathrm{NO}^{\circ}$ has been reported in patients with asthma and allergic rhinitis. Importantly, NO` suppresses the activity of the heme enzyme IDO1, which could explain the higher tryptophan levels. Thus, inhibitors of inducible NO" synthase should be reconsidered as candidates for antiallergic therapy out of season that may abrogate the arrest of IDO- 1 by decreasing the production of NO'. Considering its association with the pathophysiology of atopic disease, tryptophan metabolism may play a relevant role in the pathophysiology of allergic disorders.

(c) 2016 S. Karger AG, Basel

\section{KARGER}

E-Mail karger@karger.com www.karger.com/iaa
(C) 2016 S. Karger AG, Basel

$1018-2438 / 16 / 1694-0203 \$ 39.50 / 0$
Correspondence to: Prof. Dr. Dietmar Fuchs

Division of Biological Chemistry, Biocenter, Innsbruck Medical University Innrain 80

AT-6020 Innsbruck (Austria)

E-Mail dietmar.fuchs@i-med.ac.at 


\section{Introduction}

The incidence of allergy and asthma has increased drastically in the past few decades. Today, allergy and asthma are among the most common chronic diseases in the world. More than 130 million people are affected by asthma. Also, food allergy rates are on the rise. Interestingly, there is a lower prevalence of allergic diseases in developing countries, though this discussion is very complex.

A multitude of exogenous factors, for example higher exposure to indoor allergens, increased environmental pollution, changes in diet or breastfeeding, could be the reason for the increase in atopic diseases. However, clear relations and evidence demonstrating definitive risk factors are still lacking. A link between Western lifestyle habits and the development of allergy might exist, but the connection continues to be strongly debated [1]. Nevertheless, certain childhood infections seem to have a protective effect for the development of atopy and allergic diseases in later life. A higher state of allergic sensitization often occurs in newborns, and is even hypothesized in utero [2], but is reduced in children from large families and those who attend daily child care [3-5]. These observations suggest that a frequent contact with infections could have protective effects on children $[1,3]$.

The main explanatory theories for the increase in atopic diseases are improved hygienic conditions [6] and profound changes in nutrition. Nowadays, there exist improved sanitation and living conditions, vaccinations and antimicrobial therapies, and most people have less contact to microbes. Also, the role of gut microbiota has gained increasing attraction. Immune stimulations by microbes are considered to be necessary to counter the consolidation of the atopic responder type, as was concluded from the hygiene hypothesis $[3,6]$. Furthermore, human nutrition has changed considerably. Food preservation and sterilization reduces microbial exposure and pasteurization has largely replaced drying and fermentation [7]. Food preservatives have become more and more popular in the advent of globalization, as food is shipped and offered all over the world and needs to be conserved over a long period of time. Many commonly used preservatives are antioxidative substances, which can inhibit the oxidation of food components $[8,9]$. In addition, the daily application of chemicals in the form of care products such as cosmetics or sunscreens has drastically increased, as has the exposure to fragrance compounds such as perfumes or air refreshers. Exposure to these is most relevant for the development of delayed (type IV) sensitivity reactions.
Higher serum concentrations of the essential amino acid tryptophan were observed in adult patients with pollen allergy compared to healthy blood donors [10]. Interestingly, higher levels of tryptophan were associated with a nonresponse to subcutaneous immunotherapy (SCIT). These observations hint at the influence of cytokine profiles on tryptophan metabolism. The biochemical breakdown of tryptophan by the enzyme indoleamine 2,3-dioxygenase-1 (IDO-1) is controlled via proinflammatory stimuli, the most potent being the Th1-type cytokine interferon- $\gamma($ IFN- $\gamma)$.

\section{Tryptophan}

L-Tryptophan is one of nine essential amino acids. Absorbed tryptophan circulates in its free form or is bound to albumin in the peripheral blood stream. Average serum levels of total tryptophan in healthy blood donors are reported to be $73 \pm 14.9 \mu \mathrm{mol} / \mathrm{l}[11]$.

Tryptophan is metabolized by three different biosynthetic pathways: (a) the formation of kynurenine derivatives, which represents the major route, (b) the generation of serotonin, a neurotransmitter and precursor of melatonin [12, 13], and (c) the biosynthesis of proteins (fig. 1). To generate kynurenine, tryptophan is oxidized by cleavage of the indole ring moiety, which is achieved either by the enzyme tryptophan 2,3-dioxygenase (TDO) or by IDO-1 and IDO-2. TDO is primarily expressed in the liver and is inducible by tryptophan levels or corticosteroids $[13,14]$. IDO- 1 is induced by various inflammatory cytokines, with the most prominent being IFN- $\gamma$, and is expressed in numerous cells such as macrophages, microglia, neurons and astrocytes, and also epithelial cells and fibroblasts [15]. A recently discovered isotype enzyme of IDO-1, denominated as IDO-2, shows similarities to IDO-1, but differs in its expression pattern, substrate specificity and downstream signaling pathways [13].

IDO-1 plays an essential role within the immune response and was investigated as biomarker for the inflammation status in humans in several studies [12]. IDO-1 inhibits the proliferation of tumor cells and pathogens, as well as of immune cells, by the depletion of tryptophan and/or by production of bioactive catabolites. Tryptophan catabolites from the kynurenine pathway and the serotonin/melatonin pathway link tryptophan metabolism to neurology [16], providing a biochemical rationale for many neuropsychoimmunological manifestations and comorbidities that accompany chronic diseases. The 
Fig. 1. The immune system. Th1-type cytokine IFN- $\gamma$ is the most important inducer - indicated by a circled plus sign - of tryptophan catabolizing enzyme IDO-1. Breakdown of tryptophan in the kynurenine pathway leads to the accumulation of metabolites, some of which were found to induce Tregs, thus slowing down T cell activation - indicated by a circled minus sign. Lowering of tryptophan due to degradation by IDO-1 limits protein biosynthesis and inhibits growth, which also affects $\mathrm{T}$ cell development and proliferation. Some of the tryptophan catabolites exert effects on brain tissue and thus can affect brain cell function, impairing cognition and mood. In addition, tryptophan is a precursor of serotonin and melatonin, which are important for sleep, memory and mood. 3-OHAA = 3-Hydroxyanthranilic acid; 3HO kynurenine = 3-hyroxykynurenine; CNS = central nervous system; GIT $=$ gastrointestinal tract.

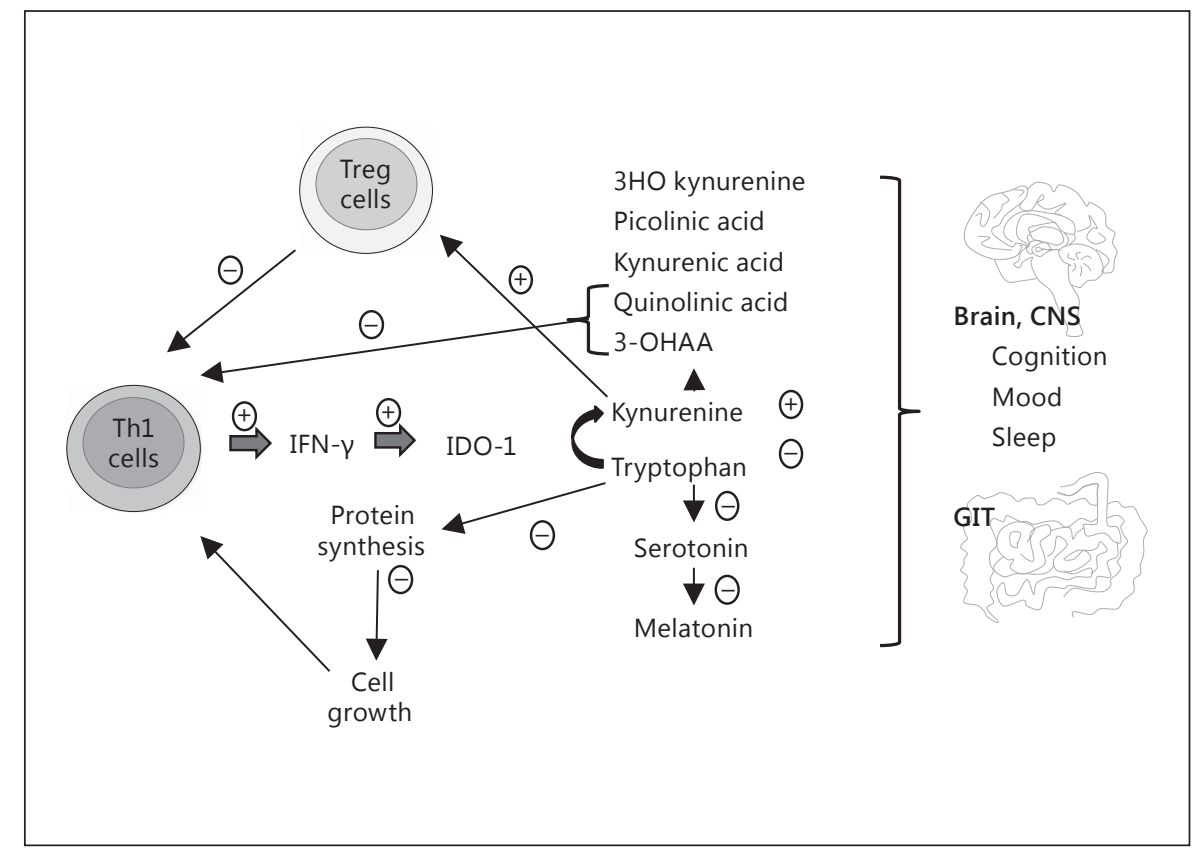

third pathway represents tryptophan as a component of proteins. Thus, in the case of an insufficient supply of tryptophan or in situations of excessive breakdown of the amino acid, a number of symptoms can emerge, including neuropsychiatric as well as immunological abnormalities (table 1).

\section{Tryptophan and Its Influence on the Immune System}

One of the first conditions in which a significant decline in tryptophan concentrations was observed, was during pregnancy [21], while levels normalized during the puerperium. A role of activated IDO-1 was indicated by the increase in the kynurenine to tryptophan ratio (Kyn/Trp) and because Kyn/Trp correlated with concentrations of the immune activation marker neopterin [21, $22]$. The decline of tryptophan was suspected to relate to a certain type of memory loss, which women may experience during the course of pregnancy, but the actual reason for the accelerated breakdown of tryptophan could not be determined. Soon after, Munn et al. [23] demonstrated in a mouse model that IDO-1 activation represents an important aspect in the establishment of immunotolerance against the fetus and established the placenta as an immunoprivileged site to prevent rejection of the fetus. Further studies by other groups confirmed and extended the role of tryptophan breakdown and IDO-1 in
Table 1. Some neuropsychoimmunological implications of tryptophan metabolism

Tryptophan and the downstream metabolites kynurenine and 3-hydroxykynurenine can cross the blood-brain barrier [17]

Tryptophan can also be metabolized by brain-resident immune cells, microglia, astrocytes and neurons, although downstream metabolism differs between the cell types [13]

Downstream metabolites can negatively affect neurological functions, e.g. quinolinic acid [17], or act as neuroprotectants, such as kynurenic acid $[18,19]$

Serotonin (5-hydroxytryptamine) is formed from 5-hydroxytryptophan [13], and a low concentration of this neurotransmitter may precipitate neuropsychiatric symptoms like depression or other mood disorders [20]

the induction of immunological tolerance. Thus, tryptophan metabolism was discovered to be strongly involved in immunomodulation [24].

In parallel, great attention was paid to the quantification of tryptophan breakdown (Kyn/Trp) as a biomarker of the activated immune system in various immunopathologies, such as infections, autoimmune and neurodegenerative disorders, and allergy [10, 12, 25-27]. IFN- $\gamma$ stimulated IDO-1 activity is drastically enhanced during the proinflammatory Th1-type immune response and IDO-1 contributes to the pathogen defense by depriva- 
tion of the essential amino acid tryptophan. Furthermore, reactive oxygen species (ROS) and reactive nitrogen species (RNS) are produced in high quantities [28], and these compounds are commonly known to interfere with target cells or pathogens by oxidation and/or nitration of vital cellular structures. Also, the activation of neopterin formation via enzyme GTP cyclohydrolase 1 (GTP-CH-I) and of inducible nitric oxide synthase (iNOS), as well as the induction of several other immune effector pathways, is caused by IFN- $\gamma[25,29]$.

For the balance of immune responses, Th1 and Th2 responses can cross-regulate each other [30]. This can be achieved by the activation of redox-sensitive signaling cascades, where oxidative conditions support Th1-type development, while an excess of antioxidant compounds, regarded as 'antioxidant stress', can lead to a shift towards allergic Th2-type immune responses [7, 31, 32]. The differentiation of specialized Thelper lymphocytes is driven by specific cytokines that are expressed in the microenvironment [33]. Also, the interaction strength between the $\mathrm{T}$ cell antigen receptor and the antigen can influence the direction of differentiation. Th2-type cells predominate in allergic reactions and asthma, IL-4, IL-5 and IL-13, representing prominent cytokines released from these cells [34]. They mediate antibody responses, especially IgE production, and control infections by helminths [35].

Although IDO-1 activation is initiated in a Th1-type setting, chronic activity leads to immunosuppression due to reduced Th1 cell proliferation and the activation of regulatory T cells (Tregs), a Th cell subset that is involved in the maintenance of immunological self-tolerance and limits potential collateral tissue damage $[33,36]$. Of note, the tryptophan catabolite kynurenine is shown to act as an endogenous ligand of the arylhydrocarbon receptor (AHR), and this interaction induces the differentiation of Tregs $[37,38]$ in addition to the role of AHR as a sensor of the outside environment and as an inducer of cytochrome P450 (CYP) enzyme expression.

\section{Diagnostic Impact of Tryptophan Breakdown and Neopterin Production}

The Th1-type cytokine IFN- $\gamma$ is the most important trigger for the production and release of neopterin in human/primate monocyte-derived macrophages. However, in dendritic cells (DCs) and other monocyte-derived cells, such as astrocytes, other interferons are of a similar strength to induce neopterin production and IFN- $\gamma$. Therefore, in human body fluids like blood, urine and ce- rebrospinal fluid, neopterin represents a stable biomarker of immune activation, which is rather stable and can be easily determined $[22,39]$. Due to the common immunostimulatory background, neopterin production and tryptophan breakdown are not only induced in parallel in vitro [40] but also in patients [12]. Several in vivo studies confirm the association between altered neopterin concentrations and tryptophan breakdown rates, as detected, for example, in serum samples of patients with infectious diseases, like HIV, gynecological cancer, malignant tumors, cardiovascular disease, neurodegenerative disorders or diseases associated with normal aging processes [12, 4145]. Both pathways turned out to represent robust and strongly predictive immune activation biomarkers. Neopterin concentrations can be measured with commercially available ELISA assays. Tryptophan and kynurenine concentrations are usually measured with high-performance liquid chromatography, and IDO-1 activity can be estimated by Kyn/Trp concentrations [45].

In vitro, a high neopterin output by activated human monocyte-derived macrophages has been shown to be associated with a strong release of hydrogen peroxide $\left(\mathrm{H}_{2} \mathrm{O}_{2}\right)$ [46]. In line with this observation, higher neopterin concentrations in patients with coronary artery disease, for example, were found to concur with low concentrations of serum antioxidants [47]. This fact implies that neopterin concentrations can also serve as a sensitive indirect marker of oxidative stress during immune activation [22].

\section{The Immune System and Allergy}

Currently, great attention is being paid to the role of the human innate immune system as it has been shown to be strongly activated during allergic responses. In brief, antigen-presenting cells absorb an allergen and initiate the signal transduction for $\mathrm{T}$ cell development within the Th2-type direction that is considered important in the pathogenesis of allergic diseases. Th2-type cell activation leads to IL-4, IL-5 and IL-13 cytokine expression. These cytokines lead to the accumulation of a high number of eosinophils and mast cells, thus boosting systemic inflammation, as these cells again start to produce large numbers of cytokines, chemotactic factors or free radicals, which ultimately leads to enhanced vascular permeability and persistent inflammation [48, 49]. Furthermore, these cytokines can interact with their receptors to stimulate allergen-specific IgE production. High levels of IgE circulate in the blood and bind to the high-affinity 
IgE receptors (FceRI) of mast cells or basophiles to activate histamine release, which is the main inductor of an allergic disease [50]. At this time point, the sensitization to a specific allergen is stored. If this antigen is present at another time, it can bind to the IgE of mast cells and activates several cascades, such as vasodilation, mucous secretion and nerve stimulation of muscle contraction [50].

It has been argued that a decreased exposure to pathogens in early childhood may result in an insufficient stimulation of Th1-type cells, which leads to a diminished capability to counterbalance the expansion of Th2-type cells and, thus, results in a predisposition to allergy $[3,4]$. High IgE levels may indicate atopy, which underlies allergic diseases, such as asthma, rhinoconjunctivitis and eczema. However, not every Th2-type response is characterized by IgE production.

\section{Tryptophan in Allergy}

It is well accepted that Th1- and Th2-type cytokines cross-regulate each other [34]. Allergic inflammation is characterized by the upregulation of Th2-type cytokines and downregulation of Th1-type cytokines, such as IFN- $\gamma$. IDO- 1 is widely recognized for its immunoregulatory and tolerance-inducing role in infection, pregnancy, autoimmunity and neoplasia, but the control of allergic inflammation has also been attributed to the enzyme. It was recently reported that experimentally induced exacerbation of rhinovirus asthma was related to systemic tryptophan and quinolinic acid concentrations, and it was confirmed that pulmonary IDO-1 activities were lower and serum tryptophan concentrations higher in patients with allergic asthma [51]. Von Bubnoff and Bieber [52] judged the tryptophan breakdown by IDO- 1 as one of the central regulatory pathways in allergy development.

In this regard, effects of tumor necrosis factor alpha (TNF- $\alpha$ ) on IDO- 1 could be of interest. Although TNF- $\alpha$ is considered a proinflammatory cytokine, which is predominantly associated with Th1-type reactions, it is involved in allergic respiratory reactions since it is released by mast cells and macrophages as well as from airway epithelial cells $[53,54]$. Interestingly, a high spontaneous release of TNF- $\alpha$ and IFN- $\gamma$ were reported from cultures of bronchoalveolar lavage-derived leukocytes but not from peripheral blood mononuclear cells (PBMCs) of patients with bronchial asthma [55]. Although TNF- $\alpha$ alone cannot induce IDO-1 activity, it acts synergistically to IFN- $\gamma[56]$.

Tryptophan Metabolism in Allergic Disorders
In human PBMCs in vitro it was observed that the typical Th2-type cytokines IL- 4 and IL- 10 counteract IFN- $\gamma$ and Th1-mediated pathways [57]. Upon exposure to IL-4 or IL-10, a lower stimulatory effect of IFN- $\gamma$ was observed, which resulted in a diminished tryptophan breakdown rate and lower neopterin levels. By contrast, the Th1-type cytokine IL-12 had the opposite effect and costimulated both biochemical pathways. Thus, exposure of PBMCs to Th2-type cytokines was reflected by higher tryptophan concentrations in culture supernatants because the breakdown of the amino acid was suppressed.

Severe allergic rhinitis has a huge impact on healthrelated quality of life and/or work, and it is associated with the dysfunction of $\mathrm{T}$ cell responses, in which the antigen induces mast cell activation by allergen-specific IgE. Furthermore, allergic rhinitis and asthma are often comorbid diseases. Persistent inflammation of the nasal mucosa may develop, which is the main relevant pathophysiological feature in allergic rhinitis $[49,50]$. Frequent treatment with aspirin, anti-inflammatory agents or antibiotics can inhibit Th1-type immune response and strengthen the development of Th2-type responses and cause allergic symptoms $[58,59]$. Interestingly, exposure of PBMCs to aspirin or salicylic acid had a suppressive effect on neopterin production and tryptophan breakdown similar to that of Th2-type cytokines [58]. Inhibition of IFN- $\gamma$ - and as a result also of IDO- 1 activity - decreases the Th1-type immune response. These observations emphasize that allergy may result from a shift of Th1- towards Th2-type immunity.

AIT (allergen-specific immunotherapy) is widely used to treat asthma and allergic rhinitis, and to modify the disease development. AIT is typically used when medication or environmental changes cannot control asthma or allergic rhinitis symptoms. There are two desensitization procedures: SCIT, where the allergens are injected subcutaneously to the patients, also known as 'allergy shots', and, in contrast, sublingual immunotherapy (SLIT), whereby the allergen is provided as drops to the sublingual area for local absorption. The outcome of both treatments seems to be equal [60], although some studies have claimed that SCIT might have better results [61]. SCIT is well tolerated [61] and has been used for many decades. SLIT is also a very old method, which is not well established in the USA, but in Europe it is still a commonly used treatment. SLIT seems to be a safer method for the treatment of children [62].

Higher serum tryptophan concentrations were observed in 44 adult patients with pollen allergy compared to healthy blood donors [10]. A study of patients with al-

Int Arch Allergy Immunol 2016;169:203-215 
lergic rhinitis before and after SCIT reported higher tryptophan levels in atopics compared to healthy blood donors, while there were no differences in kynurenine concentrations. The Kyn/Trp ratio was slightly but not significantly lower in atopics, whereas levels of serum neopterin, a marker of oxidative stress and cellular immune activation, tended to be at the upper limit of normal. Interestingly, higher levels of tryptophan were preferentially observed in nonresponders to SCIT. Thus, it was concluded that tryptophan concentrations could help to predict the outcome of SCIT [63].

A further study confirmed higher tryptophan levels in patients with pollen allergy, but this observation was made only during the off-pollen season and not in season [64]. Notably, the higher tryptophan levels observed in our first study [10] were also measured in patients before they received desensitization therapy and thus related to the off-pollen season. These results only partially agree with the earlier findings by von Bubnoff et al. [65], who described a difference between tryptophan breakdown rates (Kyn/Trp) in-season versus off-season. In their study asymptomatic atopic patients $(\mathrm{n}=12)$ presented with higher Kyn/Trp levels than symptomatic patients $(\mathrm{n}=12)$, but this was only true in-season, no such differences were observed during the off-season. During the pollen season, symptomatic atopic patients had lower $\mathrm{Kyn} / \mathrm{Trp}$ than asymptomatic subjects, with nonatopic patients lying in the middle. Kynurenine levels followed the same trend, but the higher tryptophan levels in symptomatic atopic patients suggest a special relevance of higher tryptophan for the lower $\mathrm{Kyn} / \mathrm{Trp}$ ratios found, which is similar to the findings in rhinitis patients in our study. Von Bubnoff et al. [65] concluded that higher IDO-1 activity in asymptomatic individuals limits allergic inflammation.

In summary, patients with pollen allergy seem to have a distinct IDO-1 activity pattern with higher tryptophan levels due to a less expressed breakdown out of season. However, tryptophan levels decline towards normal values in spring, when under allergen exposure tryptophan breakdown becomes initiated. The higher tryptophan levels during winter could represent a consequence of the chronic Th2-type immune response in summer due to counterregulation.

In a healthy state there is only a very low basal activity of IDO, but tryptophan and kynurenine levels have been shown to correlate in the blood of healthy donors. A possible (primary or additional) role of TDO activation should not be disregarded, and is especially important when no correlation between $\mathrm{Kyn} / \mathrm{Trp}$ and neopterin is observed in patients [10]. The hepatic enzyme TDO regulates the concentration of tryptophan in the plasma, and its activity is regulated by tryptophan levels. However, Thomas et al. [66] suggest that $\mathrm{NO}^{\circ}$ would also inhibit TDO activity in a similar fashion to that of IDO. If both tryptophan to kynurenine-converting enzymes were inhibited by $\mathrm{NO}^{\circ}$, kynurenine levels would not change. In addition, the activity of kynurenine downstream metabolizing enzymes could be affected in allergy, but at present there are no data available that would justify such a conclusion. Thus, further investigations of the tryptophan-kynurenine axis in different types of allergy are of great interest.

Beside typical nasal symptoms like itching, sneezing, rhinorrhea or obstruction [67], many allergic rhinitis patients also exhibit nonnasal symptoms as behavioral changes, such as tiredness, somnolence, depression, apathy and impaired attention, which can impair quality of life $[68,69]$. It can be hypothesized that the tryptophan pathway, and as a result also serotonin production, plays an important role in allergy and may contribute to neuropsychiatric and neurovegetative symptoms in these patients (table 1). Concentrations of serotonin, which is not only another tryptophan metabolite but also another substrate of IDO-1, were also found to be higher out of season than in season in patients with pollen allergy [68]. Low serotonin levels in allergic rhinitis patients in season upon pollen allergen exposure were strongly related with behavioral impairment, as was assessed by quality of life questionnaires. As in other clinical inflammatory conditions, tryptophan availability is strongly involved in the pathogenesis of mood disorders and depression, and abnormal tryptophan concentrations may be involved in the development of neuropsychiatric symptoms, while serotonin production is decreased [25] or may also be above normal. Thus, serotonin can serve as a biomarker of behavioral symptoms during an allergic response. In contrast to subnormal serotonin, high levels could precipitate symptoms of the serotonin syndrome, which is a life-threatening disease, characterized by the clinical triad of mental status changes, autonomic hyperactivity and neuromuscular abnormalities [70].

\section{NO in Allergy}

The reason for the higher tryptophan concentrations in patients outside of the pollen season remains obscure. However, specific interactions of $\mathrm{NO}^{\circ}$ with IDO-1 could be important in this respect [71]. $\mathrm{NO}^{\circ}$ metabolism in allergic disease has an equivocal role. Elevated arginase ac- 
tivity was reported to reduce arginine availability for constitutively expressed NO synthases (NOS). Reduced levels of the bronchodilating and anti-inflammatory molecule NO could contribute to allergic airway obstruction and inflammation. Otherwise, increases in iNOS in the airway epithelium and in inflammatory cells have been reported in asthma. The fraction of exhaled NO', FeNO, the most extensively studied biomarker of airway inflammation, is elevated in asthma patients compared to healthy controls [72].

Exhaled breath from patients with allergic rhinitis or asthma has been shown to contain higher NO levels compared to healthy controls. Exhaled $\mathrm{NO}^{\circ}$ was demonstrated to be significantly elevated in allergic rhinitis during the nonpollen season, whilst others reported a further increase in the pollen season $[73,74]$. Plasma NO metabolite levels could not be related to asthma, allergic sensitization or allergic rhinitis disease phenotypes in a study involving 523 individuals [75]. In contrast, Unal et al. [76] reported elevated levels of serum nitrite/nitrate in allergic rhinitis patients compared to controls with no allergy or atopy history, and Ciprandi et al. [49] further showed that serum nitrite concentrations were found to be higher in allergic rhinitis patients outside of the pollen season and that concentrations correlate with symptom severity. It can be speculated that there is only a partial overlap in the regulatory pathways that are associated with increased exhaled NO* levels and nitrite/nitrate levels in the circulation.

Importantly, $\mathrm{NO}^{\circ}$ can reversibly inhibit IDO- 1 activity by binding to the active heme site $[66,77]$. Thus, when $\mathrm{NO}^{*}$ formation is increased, an inhibition of IDO-1 becomes more likely, and as a consequence absolute tryptophan concentrations increase [71] (fig. 2). The increase in tryptophan in atopics out of season could be explained by a suppression of IDO-1 activity through the enhanced availability of NO: Importantly, no inhibitory activity on GTP-CH-I, the key enzyme for neopterin production, is known for NO: This would agree with the independent development of tryptophan and neopterin concentration in patients with allergic rhinitis, for example mast cells can produce IFN- $\gamma$ and stimulate the production of neopterin in monocyte-derived macrophages or DCs, while $\mathrm{NO}^{*}$ formation is initiated in endothelial cells and consequently IDO- 1 activity becomes arrested by the presence of NO:

Inhibitors of iNOS have already been considered as candidates for an antiallergic therapy [78] without considering their influence on IDO-1. IDO-1 and iNOS are both induced by IFN- $\gamma$. By diminishing $\mathrm{NO}^{\circ}$ production,

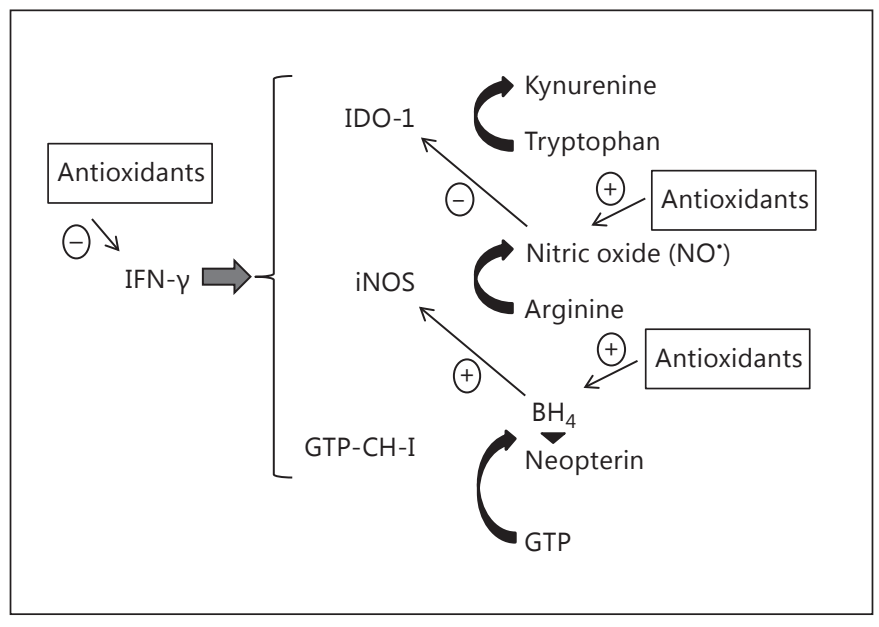

Fig. 2. As part of its antimicrobial and tumoricidal properties, IFN- $\gamma$ induces the enzymes GTP-CH-I, iNOS and IDO-1. Antioxidant compounds stabilize $\mathrm{BH}_{4}$, the cofactor of iNOS, thus supporting the production of $\mathrm{NO}^{\circ}$, and also the life span of $\mathrm{NO}^{\circ}$ is prolonged in a reductive milieu. $\mathrm{NO}^{\circ}$ slows down IDO-1 activity, which may increase tryptophan availability. Antioxidants are also capable of suppressing Th1-type immune responses.

iNOS inhibitors may abrogate the IDO-1 arrest. Based on the available data, treatment with iNOS inhibitors should be more effective outside of the pollen season than during the season [49]. iNOS inhibitors block NO production and can thereby promote IDO- 1 activity. However, the interference of $\mathrm{NO}^{\circ}$ and IDO- 1 could be cell specific. In stimulated monocyte-derived cells, ROS are concomitantly produced with $\mathrm{NO}^{\circ}$ and give rise to the cell-toxic peroxynitrite $\left(\mathrm{ONOO}^{-}\right)$, whereas in other cells, because of the absence of the superoxide anion $\left(\mathrm{O}_{2}^{-}\right)$, NO is hardly oxidized and continuously exerts its inhibitory effect on IDO-1. This can be established by an excess of antioxidants, which can stabilize the iNOS cofactor 5,6,7,8tetrahydrobiopterin $\left(\mathrm{BH}_{4}\right)$ and guarantees high $\mathrm{NO}^{\circ}$ production. Furthermore, other NOS enzymes that are not induced by IFN- $\gamma$ can continue to produce $\mathrm{NO}^{\circ}$ and inhibit IDO.

$\mathrm{BH}_{4}$ is a pteridine derivative and is required for the correct function of several monooxygenases, including iNOS. However, in human and primate macrophages, there is a lack of the enzyme 6-pyruvoyl tetrahydrobiopterin (PTPS), to produce $\mathrm{BH}_{4}$ and, instead, neopterin accumulates. As a result of this biochemical peculiarity, human and primate monocyte-derived cells produce high amounts of neopterin at the expense of $\mathrm{BH}_{4}$ and, in the absence of sufficient amounts of $\mathrm{BH}_{4}$, the proper function of enzyme iNOS is also diminished, and so is $\mathrm{NO}^{\circ}$ output 
$[29,79,80]$. In contrast, human fibroblasts or endothelial cells preferentially produce $\mathrm{BH}_{4}$, and thus also form $\mathrm{NO}^{\circ}$ sufficiently. Due to this distinct availability of $\mathrm{BH}_{4}$ versus neopterin in humans and mice or rat monocytic cells, any conclusion derived from a mouse or rat animal model system is highly questionable when immunological pathways involving monocyte-derived macrophages or DCs are concerned.

NO* synthesis is not only cell type specific, but also the cell microenvironment is important for the activity of the three different NOS isoforms [81]. Several cross-talks have been described for $\mathrm{NO}^{\circ}$ and IDO-1. For example, tryptophan and the tryptophan-kynurenine pathway metabolite 3-hydroxyanthranilic acid can inhibit iNOS at the expression and catalytic level [77].

When $\mathrm{BH}_{4}$ levels become deficient, the oxygenase domains of NOS enzymes produce $\mathrm{O}_{2}{ }^{-}$instead of NO${ }^{*}$. The produced $\mathrm{O}_{2}{ }^{-}$can promote further reactions to form other ROS/RNS, such as $\mathrm{ONOO}^{-}$or $\mathrm{H}_{2} \mathrm{O}_{2}$, which can disturb the redox balance and ultimately lead to cellular injury and inflammation. Toxic ROS products like $\mathrm{H}_{2} \mathrm{O}_{2}, \mathrm{O}_{2}{ }^{-}$or $\mathrm{ONOO}^{-}$can suppress the growth of target cells and pathogens $[82,83]$, but also cause the dysfunction of protective cellular antioxidant mechanisms in inflamed tissues, and a high oxidative stress milieu can develop [78, 84]. A high degree of oxidative stress can activate signaling cascades, such as mitogen-activated protein kinase (MAPK), transcription factor nuclear factor $-\kappa \mathrm{B}(\mathrm{NF}-\kappa \mathrm{B})$, and activator protein dependent pathways, and initiate the expression of proinflammatory cytokines, such as TNF- $\alpha$ and IL-1, chemokines and adhesion molecules [85]. The increased ROS production can further diminish $\mathrm{BH}_{4}$ availability through the oxidation of the oxidation-sensitive molecule $\mathrm{BH}_{4}$ itself [86].

\section{Food Antioxidants, Tryptophan Metabolism and Food Allergy}

Antioxidant exposure and uptake has dramatically increased in recent decades. Food and beverages are very often supplemented with vitamins such as A, C or E, which is done through the conviction that this should improve the consumer's health status. However, meta-analyses have demonstrated that supplemented antioxidant vitamins may even increase mortality rather than reducing it [87], especially vitamins $E$ and $A$, and $\beta$-carotene also seem to exert adverse effects.

Today, antioxidants are supplemented to almost every food or beverage, so it is not easy to avoid overexpo- sure. However, a well-functioning human organism does not need extra antioxidant supplementation as the content in the normal Western diet is sufficient. While extra vitamins are usually advertised within marketing concepts for healthy foods, this is not the case for food preservatives and colorants, which are usually only declared in fine print. Food preservatives like sodium sulfite or benzoate, and also colorants like curcumin or betalain, are widely known for their antioxidant activity. For all these compounds significant suppressive effects on Th1-type immune responses, including neopterin production and IDO-1 activity, have been reported in in vitro studies $[9,88,89]$. An excess of food preservatives or antioxidants may therefore increase allergy risks [7, 31].

Food allergy is often not strictly an allergy, although today every adverse effect of food is denominated by the public as an allergy. In its strict sense, food allergy is an adverse reaction to the food itself and the classical immune mechanism is indicated by the presence of specific IgE antibodies. The diagnosis will be taken after a case history, the demonstration of IgE sensitization by a skin-prick or an in vitro test, and will be confirmed by a positive oral provocation [90]. By contrast, food intolerance is considered as a 'nonimmune'-mediated adverse reaction to food compounds. There are enzymatic (for example lactose intolerance, lactase deficiency), pharmacological (reactions against biogenic amines, histamine intolerance) or undefined food intolerances (against food additives). Interestingly, under such conditions huge amounts of hydrogen gas $\left(\mathrm{H}_{2}\right)$ are produced and exhaled, $\mathrm{H}_{2}$ under certain circumstances itself being a strong antioxidative compound. It has to be kept in mind that not every sign of sickness after food intake indicates an allergy. Notably, a preliminary study reported lower tryptophan breakdown in patients with food allergy [91]. In an NMR-based metabolome study, increased levels of tryptophan and tyrosine could be measured in the plasma of peanut-allergic compared to peanut-tolerant subjects following the ingestion of peanut [92].

Recently performed studies have reported an association between fast food consumption and the prevalence of asthma, rhinoconjunctivitis and eczema in children and adolescents [93]. In addition, antioxidants or additives may disturb the endogenous appetite and regulatory satiation circuits. On the one hand, antioxidants may suppress tryptophan breakdown by IDO-1 [94] and thus increase the availability of tryptophan for serotonin production, and as a consequence improve mood. On the 
other hand, tryptophan metabolic changes may also contribute to weight gain after a calorie-restricted diet [95] when tryptophan levels decline under starvation conditions, which increases carbohydrate craving as a substitute for brain serotonin [96] followed by weight gain. This sequence of events can explain the often observed yo-yo effect, also known as weight cycling, when people rapidly gain weight after a diet, and it may relate to the coincidence of obesity and allergy. Of note, de Theije et al. [97] showed that a food-allergic reaction to cow's milk protein in mice led to increased serotonin and decreased 5-hydroindolacetic acid levels in the intestine, and dysregulated neurobiochemical circuits induced an autistic-like phenotype in the animals. Food allergies and sensitivities seem to be more frequent in children with autism spectrum disorder [98]. Thus, the link between food allergy and psychopathologies has been discussed, although difficulties in diagnosis and study design can lead to ambiguous results [99].

The histamine content of beverages and food also has to be taken in consideration. As mentioned above, histamine is known to trigger acute symptoms like acute rhinitis, bronchoconstriction, diarrhea or cutaneous wheal. It has a strong activity on endothelium and bronchial or smooth muscle cells and also modulates chronic inflammatory events [100]. Histamine is important in the early- and late-phase response to soluble antigens. It increases the vascular permeability and is involved in the recruitment, adherence and activation of inflammatory cells [101]. Histamine content is increased in preserved food and thus could play an important role in the precipitation of allergic symptoms if excessive histamine uptake can trigger allergy development. Moreover, an inhibitory effect of histamine on neopterin formation in myelomonocytic cells has been described in vitro [102].

However, other environmental factors, such as air pollution, can be responsible for increasing the appearance of allergy. Carbon monoxide (CO) represents an important compound derived from the incomplete burning of fossil organics. CO accumulates in the blood or is inhaled during cigarette smoking and can downregulate Th1type immune responses via the inhibition of IFN- $\gamma$, inhibit IDO-1 activity and, thus, activate Th2-type immunity $[103,104]$. Thus, an excess of antioxidants can explain the connection of obesity, smoking or pollution and their association with the increase in allergies [7, 9, 31, 105]. The higher availability of tryptophan and thus serotonin in smokers may enhance mood and thereby support addiction to tobacco smoking.

Tryptophan Metabolism in Allergic Disorders

\section{Physical Exercise and Allergy}

Physical exercise is the most convenient way to escape from antioxidative stress caused by an excess intake of antioxidative compounds. Sport helps not only in burning fat, it especially oxidizes even stronger antioxidants like vitamins, spices and food preservatives. This interaction may help to explain findings that supplementation with antioxidant vitamins was found to slow down the antioxidant defense response induced by physical exercise and sports $[106,107]$. However, oxidative challenge will depend on the mode, intensity and duration of exercise. The underlying signaling network of exerciseinduced long-term adaptations is even more complex [108]. There is consent that moderate sports and physical exercise can be recommended to combat allergic responses, whereas high-intensity exercise may even contribute to the precipitation and worsening of allergy and asthma.

Many studies have demonstrated an increase in circulating cytokines following prolonged strenuous exercise. Indeed, exercise results in an increase in both proinflammatory cytokines, for example TNF- $\alpha$, and anti-inflammatory cytokines, such as IL-6, which appear to act in a hormone-like manner and be involved in increasing substrate metabolism during prolonged exercise [109]. Glycogen depletion stimulates the production of IL- 6 by the working muscles, which is then released from the muscle, resulting in an elevated plasma IL- 6 concentration during exercise [110].

Intense training can lead to a suppression of the production of specific cytokines from stimulated monocytes and $\mathrm{T}$ lymphocytes, and can induce a shift in the Th1Th2-type immune balance towards Th2-type immunity [111]. The decrease in the percentage of type-1 T cells may predispose athletes to a higher frequency of upper respiratory tract symptoms, such as allergic rhinitis and asthma [112]. The slowing down of Th1-type immune activation cascades suppresses IDO-1 activity, which on the one hand counteracts the immune defense and thus may increase susceptibility to viral infection, and on the other hand will diminish the breakdown of tryptophan [113]. Current research has led to the development of the 'noninfectious' hypothesis for upper respiratory tract symptoms in athletes, suggesting that many of the symptoms reported following exercise, such as a running nose or ocular irritation, are more likely allergic in origin than infectious [114]. Indeed, it is proposed that in chronic exercise training, the repeated exercise-induced elevations in IL-6 play a role in the reported increased incidence of

Int Arch Allergy Immunol 2016;169:203-215 
allergic disease in athletes by inhibiting Th1 and driving Th2 differentiation [115]. However, significant stimulation of tryptophan breakdown was reported recently after aerobic exercise in trained athletes [116]. These results may indicate that the initial proinflammatory insult of exercise, which is indicated by the production of several cytokines indicative for activated $\mathrm{T}$ cells and macrophages [117], could relate to the development of the finally immunosuppressed state, for example via the activation of Tregs.

The incidence of allergic disease is higher in athletes than in the general population and can impact upon athletic performance as well as future well-being. A decreased nutrient availability during prolonged high-intensity exercise may be involved in the etiology of exercise-induced immune depression. To maintain immune function, athletes are advised to avoid deficiencies of the nutrients that play an essential role in immune cell functions. Although it is not known whether hard training increases the need for dietary antioxidants - as the endogenous antioxidant defenses improve with exercise training and a balanced diet - some recent evidence suggests that regular intake of relatively high doses of antioxidant vitamins inhibits the release of IL- 6 from contracting human skeletal muscle and can also reduce the cortisol response to prolonged exercise [118], and may even increase infection and allergy risks [31]. Thus, moderate sports at higher altitude to reduce confrontation with allergens can represent a potent strategy against allergies, but excessive supplementation with antioxidant vitamins cannot be recommended because there is little evidence of any benefit, while there is now a reasonable body of evidence that the regular consumption of probiotics can modify the microbiota and influence immune function [119].

\section{Conclusion}

Significant alterations of the tryptophan metabolism have been described in patients suffering from allergy. Allergy development is characterized by Th2-type immune activation that is related to cytokine expression. The immoderate increase in allergies in the past decades posed the question of the underlying triggers. Various explanations have been taken into consideration, including the hygiene hypothesis or the impact of air and environmental pollution. There is unquestionable evidence that daily-life exposure to synthetic compounds has increased. The enormous presence of antioxidants as food additives, preservatives or colorants has become indispensable. However, the aspect of antioxidants and allergy development has to be investigated in more detail. Antioxidants can inhibit the Th1-type immune response, which can result in an insufficient clearance of infectious pathogens. The inhibition can be mediated by downregulation of IFN- $\gamma$ and/or by the inhibition of IDO-1 leading to higher tryptophan levels. The radical scavenging property of antioxidants can stabilize $\mathrm{BH}_{4}$, the cofactor for iNOS, and thus promote high NO' output. The high NO${ }^{*}$ level inhibits IDO-1 activity by binding to the catalytic domain.

To summarize, the right balance between cellular produced ROS and antioxidant uptake via nutrition is essential to support human health. We suggest that levels of $\mathrm{NO}^{\circ}$ and tryptophan are good biomarkers in allergy diagnosis and can be of value in the evaluation of the treatment response.

\section{Acknowledgements}

This work was supported by the Austrian Science Fund (FWF) grant $\mathrm{T} 703$.

\section{References}

1 Isolauri E, Huurre A, Salminen S, Impivaara $O$ : The allergy epidemic extends beyond the past few decades. Clin Exp Allergy 2004;34: 1007-1010.

2 Prescott SL: Allergic disease: understanding how in utero events set the scene. Proc Nutr Soc 2010;69:366-372.

3 Strachan DP: Hay fever, hygiene, and household size. Brit Med J 1989;299:1259-1260.

4 Krämer U, Heinrich J, Wjst M, Wichmann HE: Age of entry to day nursery and allergy in later childhood. Lancet 1999;353:450-454.
5 Yazdanbakhsh M, Kremsner PG, van Ree R: Allergy, parasites, and the hygiene hypothesis. Science 2002;296:490-494.

6 Liu AH, Murphy JR: Hygiene hypothesis: fact or fiction? J Allergy Clin Immunol 2003;111: 471-478.

7 Fuchs D: Antioxidant intake and allergic disease. Clin Exp Allergy 2012;42:1420-1422.

8 Murr C, Schroecksnadel K, Winkler C, Ledochowski M, Fuchs D: Antioxidants may increase the probability of developing allergic diseases and asthma. Med Hypotheses 2005; 64:973-977.
9 Gostner J, Ciardi C, Becker K, Fuchs D, Sucher R: Immunoregulatory impact of food antioxidants. Curr Pharm Des 2014;20:840-849.

10 Kositz C, Schroecksnadel K, Grander G, Schennach H, Kofler H, Fuchs D: Serum tryptophan concentration in patients predicts outcome of specific immunotherapy with pollen extracts. Int Arch Allergy Immunol 2008; 147:35-40.

11 Widner B, Werner ER, Schennach H, Wachter H, Fuchs D: Simultaneous measurement of serum tryptophan and kynurenine by HPLC. Clin Chem 1997;43:2424-2426. 
12 Schroecksnadel K, Wirleitner B, Winkler C, Fuchs D: Monitoring tryptophan metabolism in chronic immune activation. Clin Chim Acta 2006;364:82-90.

13 Chen Y, Guillemin GJ: Kynurenine pathway metabolites in humans: disease and healthy States. Int J Tryptophan Res 2009;2:1-19.

14 Knox WE: The regulation of tryptophan pyrrolase activity by tryptophan. Adv Enzyme Regul 1966;4:287-297.

15 Werner ER, Hirsch-Kauffmann M, Fuchs D, Hausen A, Reibnegger G, Schweiger M, Wachter H: Interferon- $\gamma$-induced degradation of tryptophan by human cells in vitro. Biol Chem Hoppe Seyler 1987;368:14071412.

16 Heyes MP, Saito K, Crowley JS, Davis LE, Demitrack MA, Der M, Dilling LA, Elia J, Kruesi MJ, Lackner A: Quinolinic acid and kynurenine pathway metabolism in inflammatory and non-inflammatory neurological disease. Brain 1992;115:1249-1273.

17 Fukui S, Schwarcz R, Rapoport SI, Takada Y, Smith Q: Blood-brain barrier transport of kynurenines: implications for brain synthesis and metabolism. J Neurochem 1991;56:20072017.

18 Klein C, Patte-Mensah C, Taleb O, Bourguignon JJ, Schmitt M, Bihel, F, Maitre M, Mensah-Nyagan AG: The neuroprotector kynurenic acid increases neuronal cell survival through neprilysin induction. Neuropharmacology 2013;70:254-260.

19 Sas K, Robotka H, Toldi J, Vécsei L: Mitochondria, metabolic disturbances, oxidative stress and the kynurenine system, with focus on neurodegenerative disorders. J Neurol Sci 2007;257:221-239.

20 Widner B, Laich A, Sperner-Unterweger B, Ledochowski M, Fuchs D: Neopterin production tryptophan degradation and mental depression: what is the link? Brain Behav Immun 2002;16:590-595.

21 Schröcksnadel H, Baier-Bitterlich G, Dapunt O, Wachter H, Fuchs D: Decreased plasma tryptophan in pregnancy. Obstet Gynecol 1996;88:47-50.

22 Murr C, Widner B, Wirleitner B, Fuchs D: Neopterin as a marker for immune system activation. Curr Drug Metabol 2002;3:175-187.

23 Munn DH, Zhou M, Attwood JT, Bondarev I, Conway SJ, Marshall B, Brown C, Mellor AL: Prevention of allogeneic fetal rejection by tryptophan catabolism. Science 1998;281: 1191-1193.

24 Mellor AL, Munn DH: IDO expression by dendritic cells: tolerance and tryptophan catabolism. Nat Rev Immunol 2004;4:762-774.

25 Widner B, Ledochowski $M$, Fuchs D: Interferon- $\gamma$-induced tryptophan degradation: neuropsychiatric and immunological consequences. Curr Drug Metabol 2000;1: 193-204.

26 Raitala A, Karjalainen J, Oja SS, Kosunen TU, Hurme M: Indoleamine 2,3-dioxygenase (IDO) activity is lower in atopic than in nonatopic individuals and is enhanced by envi- ronmental factors protecting from atopy. $\mathrm{Mol}$ Immunol 2006;43:1054-1056.

27 Widner B, Leblhuber F, Walli J, Tilz GP, Demel U, Fuchs D: Tryptophan degradation and immune activation in Alzheimer's disease. J Neural Transm (Vienna) 2000;107: 343-353.

28 Nathan CF, Murray HW, Wiebe ME, Rubin BY: Identification of interferon- $\gamma$ as the lymphokine that activates human macrophage oxidative metabolism and antimicrobial activity. J Exp Med 1983;158:670-689.

29 Werner ER, Werner-Felmayer G, Fuchs D, Hausen A, Reibnegger R, Yim JJ, Wachter H: Biochemistry and function of pteridine synthesis in human and murine macrophages. Pathobiology 1991;59:276-279.

30 Romagnani S: Regulation of the $\mathrm{T}$ cell response. Clin Exp Allergy 2006;36:1357-1366.

31 Zaknun D, Schroecksnadel S, Kurz K, Fuchs D: Potential role of antioxidant food supplements, preservatives and colorants in the pathogenesis of allergy and asthma. Int Arch Allergy Immunol 2012;157:113-124.

32 Poljsak B, Milisav I: The neglected significance of 'antioxidative stress'. Oxid Med Cell Longev 2012;2012:480895.

33 Zhou L, Chong MM, Littman DR: Plasticity of $\mathrm{CD}^{+} \mathrm{T}$ cell lineage differentiation. Immunity 2009;30:646-655

34 Romagnani S: Immunologic influences on allergy and the $\mathrm{T}_{\mathrm{H}} 1 / \mathrm{T}_{\mathrm{H}} 2$ balance. J Allergy Clin Immunol 2004;113:395-400.

35 Barth H, Berg PA, Klein R: Methods for the in vitro determination of an individual disposition towards TH1- or TH2-reactivity by the application of appropriate stimulatory antigens. Clin Exp Immunol 2003;134:78-85.

36 Hori S, Nomura T, Sakaguchi S: Control of regulatory $\mathrm{T}$ cell development by the transcription factor Foxp3. Science 2003;299: 1057-1061.

37 Fallarino F, Grohmann U, Puccetti P: Indoleamine 2,3-dioxygenase: from catalyst to signaling function. Eur J Immunol 2012;42: 1932-1937.

38 van Voorhis M, Fechner JH, Zhang X, Mezrich JD: The aryl hydrocarbon receptor: a novel target for immunomodulation in organ transplantation. Transplantation 2013;95: 983-990.

39 Fuchs D, Weiss G, Reibnegger G, Wachter H: The role of neopterin as a monitor of cellular immune activation in transplantation, inflammatory, infectious and malignant diseases. Crit Rev Clin Lab Sci 1992;29:307-341.

40 Weiss G, Murr C, Zoller H, Haun M, Widner B, Ludescher C, Fuchs D: Modulation of neopterin formation and tryptophan degradation by Th1- and Th2-derived cytokines in human monocytic cells. Clin Exp Immunol 1999; 116:435-440.

41 Fuchs D, Hausen A, Reibnegger G, Werner ER, Dierich MP, Wachter H: Neopterin as a marker for activated cell-mediated immunity: application in HIV infection. Immunol Today 1988;9:150-155.
42 Fuchs D, Avanzas P, Arroyo-Espliguero R, Jenny M, Consuegra Sanchez L, Kaski JC: The role of neopterin in atherogenesis and cardiovascular risk stratification. Curr Med Chem 2009; 16:4644-4653.

43 De Rosa S, Cirillo P, Pacileo M, Petrillo G, D'Ascoli GL, Maresca F, Ziviello F, Chiariello M: Neopterin: from forgotten biomarker to leading actor in cardiovascular pathophysiology. Curr Vasc Pharmacol 2011;9:188-199.

44 Pedersen ER, Midttun $\varnothing$, Ueland PM, Schartum-Hansen $\mathrm{H}$, Seifert R, Igland J, Nordrehaug JE, Ebbing M, Svingen G, Bleie $\varnothing$, Berge $R$, Nygård $O$ : Systemic markers of interferon$\gamma$-mediated immune activation and longterm prognosis in patients with stable coronary artery disease. Arterioscler Thromb Vasc Biol 2011;31:698-704.

45 Fuchs D, Möller AA, Reibnegger G, Stöckle E, Werner ER, Wachter H: Decreased serum tryptophan in patients with HIV-1 infection correlates with increased serum neopterin and with neurologic/psychiatric symptoms. J Acquir Immune Defic Syndr 1990;3:873-876.

46 Nathan CF: Peroxide and pteridine: a hypothesis on the regulation of macrophage antimicrobial activity by interferon gamma. Interferon 1986;7:125-143.

47 Murr C, Schroecksnadel K, Winklhofer-Roob BM, Mangge H, Böhm BO, Winkelmann BR, Maerz W, Fuchs D: Inverse association between serum concentrations of neopterin and antioxidants in patients with and without angiographic coronary artery disease. Atherosclerosis 2009;202:543-549.

48 Holt PG, Macaubas C, Stumbles PA, Sly PD The role of allergy in the development of asthma. Nature 1999;402(6760 suppl):B12-B17.

49 Ciprandi G, Tosca M, Fuchs D: Nitric oxide metabolites in allergic rhinitis: the effect of pollen allergen exposure. Allergol Immunopathol 2011;39:326-329.

50 Brown JM, Wilson TM, Metcalfe DD: The mast cell and allergic diseases: role in pathogenesis and implications for therapy. Clin Exp Allergy 2008;38:4-18.

51 van der Sluijs KF, van de Pol MA, Kulik W, Dijkhuis A, Smids BS, van Eijk HW, Karlas JA, Molenkamp R, Wolthers KC, Johnston SL, van der Zee JS, Sterk PJ, Lutter R; RESOLVE Research Team: Systemic tryptophan and kynurenine catabolite levels relate to severity of rhinovirus-induced asthma exacerbation: a prospective study with a parallelgroup design. Thorax 2013;68:1122-1130.

52 von Bubnoff D, Bieber T: The indoleamine 2,3-dioxygenase (IDO) pathway controls allergy. Allergy 2012;67:718-725.

53 Thomas PS: Tumour necrosis factor- $\alpha$ : the role of this multifunctional cytokine in asthma. Immunol Cell Biol 2001;79:132-140.

54 Calderón MA, Devalia JL, Prior AJ, Sapsford RJ, Davies RJ: A comparison of cytokine release from epithelial cells cultured from nasal biopsy specimens of atopic patients with and without rhinitis and nonatopic subjects without rhinitis. J Allergy Clin Immunol 1997;99:65-76. 
55 Cembrzynska-Nowak M, Szklarz E, Inglot $A D$, Teodorczyk-Injeyan JA: Elevated release of tumor necrosis factor- $\alpha$ and interferon- $\gamma$ by bronchoalveolar leukocytes from patients with bronchial asthma. Am Rev Respir Dis 1993;147:291-295.

56 Werner-Felmayer G, Werner ER, Fuchs D, Hausen A, Reibnegger G, Wachter $\mathrm{H}$ : Tumour necrosis factor- $\alpha$ and lipopolysaccharide enhance interferon-induced tryptophan degradation and pteridine synthesis in human cells. Biol Chem Hoppe Seyler 1989;370: 1063-1069.

57 Weiss G, Murr C, Zoller H, Haun M, Widner B, Ludescher C, Fuchs D: Modulation of neopterin formation and tryptophan degradation by Th1- and Th2-derived cytokines in human monocytic cells. Clin Exp Immunol 1999;116:435-440.

58 Schroecksnadel K, Winkler C, Wirleitner B, Schennach H, Fuchs D: Aspirin down-regulates tryptophan degradation in stimulated human peripheral blood mononuclear cells in vitro. Clin Exp Immunol 2005;140:41-45.

59 Kuo CH, Kuo HF, Huang CH, Yang SN, Lee MS, Hung CH: Early life exposure to antibiotics and the risk of childhood allergic diseases: an update from the perspective of the hygiene hypothesis. J Microbiol Immunol Infect 2013; 46:320-329.

60 Saporta D: Efficacy of sublingual immunotherapy versus subcutaneous injection immunotherapy in allergic patients. J Environ Public Health 2012;2012:492405.

61 Mungan D, Misirligil Z, Gürbüz L: Comparison of the efficacy of subcutaneous and sublingual immunotherapy in mite-sensitive patients with rhinitis and asthma - a placebo controlled study. Ann Allergy Asthma Immunol 1999;82:485-490.

62 André C, Vatrinet C, Galvain S, Carat F, Sicard H: Safety of sublingual-swallow immunotherapy in children and adults. Int Arch Allergy Immunol 2000;121:229-234.

63 Kofler H, Kurz K, Grander G, Fuchs D: Specific immunotherapy normalizes tryptophan concentrations in patients with allergic rhinitis. Int Arch Allergy Immunol 2012;159:416-421.

64 Ciprandi G, De Amici M, Tosca M, Fuchs D: Tryptophan metabolism in allergic rhinitis: the effect of pollen allergen exposure. Hum Immunol 2010;71:911-915.

65 von Bubnoff D, Fimmers R, Bogdanow M, Matz H, Koch S, Bieber T: Asymptomatic atopy is associated with increased indoleamine 2,3-dioxygenase activity and interleukin-10 production during seasonal allergen exposure. Clin Exp Allergy 2004;34:1056-1063.

66 Thomas SR, Terentis AC, Cai H, Takikawa O, Levina A, Lay PA, Freewan M, Stocker R: Post-translational regulation of human indoleamine 2,3-dioxygenase activity by nitric oxide. J Biol Chem 2007;282:23778-23787.

67 Bousquet J, Khaltaev N, Cruz AA, Denburg J, Fokkens WJ, Togias A, et al: Allergic Rhinitis and Its Impact on Asthma (ARIA) 2008 update. Allergy 2008;63(suppl 86):8-160.
68 Ciprandi G, De Amici M, Tosca M, Fuchs D, Marseglia G: Serotonin in allergic rhinitis: a role for behavioural symptoms. Iran J Allergy Asthma Immunol 2011;10:183-188.

69 Juniper EF, Guyatt GH: Development and testing of a new measure of health status for clinical trials in rhinoconjunctivitis. Clin Exp Allergy 1991;21:77-83.

70 Boyer EW, Shannon M: The serotonin syndrome. N Engl J Med 2005:352:1112-1120.

71 Ciprandi G, Fuchs D: Tryptophan, neopterin, and nitrite in allergy. Allergy 2013;67:1083.

72 Stewart L, Katial RK: Exhaled nitric oxide. Immunol Allergy Clin North Am 2012;32: 347-362.

73 Henriksen AH, Sue-Chu M, Holmen TL, Langhammer A, Bjermer L: Exhaled and nasal NO levels in allergic rhinitis: relation to sensitization, pollen season and bronchial hyperresponsiveness. Eur Respir J 1999;13:301306

74 Ciebiada M, Cichocki P, Kasztalska K, Majewski S, Gorska-Ciebiada M, Gorski P: Orally exhaled nitric oxide in patients with seasonal allergic rhinitis during natural pollen season. Am J Rhinol Allergy 2012;26:e32-e36.

75 Nadif R, Rava M, Decoster B, Huyvaert H, Le Moual N, Bousquet J, Siroux V, Varraso R, Pin I, Zerimech F, Matran R: Exhaled nitric oxide, nitrite/nitrate levels, allergy, rhinitis and asthma in the EGEA study. Eur Respir J 2014; $44: 351-360$.

76 Unal M, Eskandari HG, Erçetin N, Doğruer ZN, Pata YS: Serum nitrite/nitrate and arginase levels in patients with allergic rhinitis. ORL J Otorhinolaryngol Relat Spec 2007;69: 113-115.

77 Samelson-Jones BJ, Yeh SR: Interactions between nitric oxide and indoleamine 2,3-dioxygenase. Biochemistry 2006;45:8527-8538.

78 Hesslinger C, Strub A, Boer R, Ulrich WR, Lehner MD, Braun C: Inhibition of inducible nitric oxide synthase in respiratory diseases. Biochem Soc Trans 2009;37:886-891.

79 Werner ER, Werner-Felmayer G, Fuchs D, Hausen A, Reibnegger G, Yim JJ, Pfleiderer $\mathrm{W}$, Wachter $\mathrm{H}$ : Tetrahydrobiopterin biosynthetic activities in human macrophages, fibroblasts, THP-1 and T 24 cells. GTP-cyclohydrolase I is stimulated by interferon- $\gamma$, 6-pyruvoyl tetrahydropterin synthase and sepiapterin reductase are constitutively present. J Biol Chem 1990;265:3189-3192.

80 Andrew PJ, Mayer B: Enzymatic function of nitric oxide synthases. Cardiovasc Res 1999; 43:521-531.

81 Villanueva C, Giulivi C: Subcellular and cellular locations of nitric oxide synthase isoforms as determinants of health and disease. Free Radic Biol Med 2010;49:307-316.

82 Schroecksnadel S, Jenny M, Kurz K, Klein A, Ledochowski M, Ueberall F, Fuchs D: LPSinduced NF- $\mathrm{KB}$ expression in THP-1Blue cells correlates with neopterin production and activity of indoleamine 2,3-dioxygenase. Biochem Biophys Res Com 2010;399:642646.
83 Wink DA, Hines HB, Cheng RY, Switzer $\mathrm{CH}$, Flores-Santana W, Vitek MP, Ridnour LA, Colton CA: Nitric oxide and redox mechanisms in the immune response. J Leukoc Biol 2011;89:873-891.

84 Bowler RP, Crapo JD: Oxidative stress in allergic respiratory diseases. J Allergy Clin Immunol 2002;110:349-356.

85 Aggarwal BB: Nuclear factor- $\kappa \mathrm{B}$ : the enemy within. Cancer Cell 2004;6:203-208.

86 Kuzkaya N, Weissmann N, Harrison DG, Dikalov S: Interactions of peroxynitrite, tetrahydrobiopterin, ascorbic acid, and thiols: implications for uncoupling endothelial nitricoxide synthase. J Biol Chem 2003;278: 22546-22554.

87 Bjelakovic G, Nikolova D, Gluud LL, Simonetti RG, Gluud C: Mortality in randomized trials of antioxidant supplements for primary and secondary prevention: systematic review and meta-analysis. J Am Med Assoc 2007;297: 842-857.

88 Winkler C, Wirleitner B, Schroecksnadel K, Schennach H, Fuchs D: In vitro effects of beet root juice on stimulated and unstimulated peripheral blood mononuclear cells. Am J Biochem Biotechnol 2005;1:181-186.

89 Maier E, Kurz K, Jenny M, Schennach H, Ueberall F, Fuchs D: Food preservatives sodium benzoate and propionic acid and colorant curcumin suppress Th1-type immune response in vitro. Food Chem Toxicol 2010; 48:1950-1956.

90 Wüthrich B: Food allergy, food intolerance or functional disorder? Praxis (Bern 1994) 2009; 98:375-387.

91 Bujuktiryaki B, Sahiner UM, Girgin G, Yavuz ST, Cavkatayar O, Yilmaz AE, Birben E, Tuncer A, Baydar T, Sackesen C: The role of tryptophan-kynurenine pathway in food allergy and tolerance development. Pteridines 2013;23(suppl 1):S43-S44.

92 Peeters KA, Lamers RJ, Penninks AH, Knol EF, Bruijnzeel-Koomen CA, van Nesselrooij $\mathrm{JH}$, Knulst AC: A search for biomarkers as diagnostic tools for food allergy: a pilot study in peanut-allergic patients. Int Arch Allergy Immunol 2011;155:23-30.

93 Ellwood P, Asher MI, García-Marcos L, Williams H, Keil U, Robertson C, Nagel G; ISAAC Phase III Study Group: Do fast foods cause asthma, rhinoconjunctivitis and eczema? Global findings from the International Study of Asthma and Allergies in Childhood (ISAAC) phase three. Thorax 2013;68:351-360.

94 Jenny M, Klieber M, Zaknun D, Schroecksnadel S, Kurz K, Ledochowski M, Schennach $\mathrm{H}$, Fuchs D: In vitro testing for anti-inflammatory properties of compounds employing peripheral blood mononuclear cells freshly isolated from healthy donors. Inflamm Res 2011;60:127-135.

95 Strasser B, Berger K, Fuchs D: Effects of a caloric restriction weight loss diet on tryptophan metabolism and inflammatory biomarkers in overweight adults. Eur J Nutr 2015;54:101-107. 
96 Wurtman RJ, Wurtman JJ: Brain serotonin, carbohydrate-craving, obesity and depression. Obes Res 1995;3(suppl 4):477S-480S.

97 de Theije CG, Wu J, Koelink PJ, KorteBouws GA, Borre Y, Kas MJ, Lopes da Silva S, Korte SM, Olivier B, Garssen J, Kraneveld AD: Autistic-like behavioural and neurochemical changes in a mouse model of food allergy. Behav Brain Res 2014;261:265-274.

98 Lyall K, van de Water J, Ashwood P, HertzPicciotto I: Asthma and allergies in children with autism spectrum disorders: results from the CHARGE study. Autism Res 2015; 8:567-574.

99 Arnold LE, Lofthouse N, Hurt E: Artificial food colors and attention-deficit/hyperactivity symptoms: conclusions to dye for. Neurotherapeutics 2012;9:599-609.

100 Jutel M, Watanabe T, Akdis M, Blaser K, Akdis CA: Immune regulation by histamine. Curr Opin Immunol 2002;14:735-740.

101 Andersson M, Greiff L, Svensson C: Allergic rhinoconjunctivitis: the role of histamine. Mediators Inflamm 1994;3:171-175.

102 Gruber A, Murr C, Wirleitner B, WernerFelmayer G, Fuchs D: Histamine suppresses neopterin production in the human myelomonoctoma cell line THP-1. Immunol Lett 2000;72:133-136.

103 Naito Y, Uchiyama K, Takagi T, Yoshikawa $\mathrm{T}$ : Therapeutic potential of carbon monoxide (CO) for intestinal inflammation. Curr Med Chem 2012;19:70-76.

104 Strasser B, Gostner JM, Fuchs D: Carbon monoxide exposure may underlie the increased leukaemia risk in children living next to motor highways. Eur J Epidemiol 2015;30:1329-1330
105 Hosick PA, Stec DE: Heme oxygenase, a novel target for the treatment of hypertension and obesity? Am J Physiol Regul Integr Comp Physiol 2012;302:R207-R214.

106 Ristow M, Zarse K, Oberbach A, Klöting N, Birringer M, Kiehntopf M, Stumvoll M, Kahn CR, Blüher M: Antioxidants prevent health-promoting effects of physical exercise in humans. Proc Natl Acad Sci USA 2009; 106:8665-8670.

107 Peternelj TT, Coombes JS: Antioxidant supplementation during exercise training: beneficial or detrimental? Sports Med 2011;41: 1043-1069.

108 Steinbacher P, Eckl P: Impact of oxidative stress on exercising skeletal muscle. Biomolecules 2015;5:356-377.

109 Pedersen BK: Muscle as a secretory organ. Compr Physiol 2013;3:1337-1362.

110 Steensberg A: The role of IL-6 in exerciseinduced immune changes and metabolism. Exerc Immunol Rev 2003;9:40-47.

111 Steensberg A, Toft AD, Bruunsgaard $\mathrm{H}$ Sandmand M, Halkjaer-Kristensen J, Pedersen BK: Strenuous exercise decreases the percentage of type $1 \mathrm{~T}$ cells in the circulation. J Appl Physiol 2001;91:1708-1712.

112 Walsh NP, Gleeson M, Shephard RJ, Gleeson M, Woods JA, Bishop NC, Fleshner M, Green C, Pedersen BK, Hoffman-Goetz L, Rogers CJ, Northoff H, Abbasi A, Simon P: Position statement. Part one. Immune function and exercise. Exerc Immunol Rev 2011; $17: 6-63$
113 Gostner JM, Becker K, Sperner-Unterweger B, Überall F, Fuchs D, Strasser B: Role of tryptophan metabolism in mood, behavior, and cognition; in Mittal S (ed): Targeting the Broadly Pathogenic Kynurenine Pathway. Cham, Springer, 2015.

114 Dijkstra HP, Robson-Ansley P: The prevalence and current opinion of treatment of allergic rhinitis in elite athletes. Curr Opin Allergy Clin Immunol 2011;11:103-108.

115 Dienz O, Rincon M: The effects of IL-6 on CD4 T cell responses. Clin Immunol 2009; 130:27-33.

116 Geiger D, Schauer M, Gatterer H, Burtscher M, Fuchs D, Strasser B: Effects of exhaustive exercise on tryptophan-kynurenine metabolism in trained athletes. 12th ISEI Symposium, Cells Meet Function in Exercise Immunology, Vienna, 2015. Abstract 40:O24.

117 Sprenger H, Jacobs C, Nain M, Gressner AM, Prinz H, Wesemann W, Gemsa D: Enhanced release of cytokines, interleukin-2 receptors, and neopterin after long-distance running. Clin Immunol Immunopathol 1992;63:188-195.

118 Fischer CP, Hiscock NJ, Penkowa M, Basu S, Vessby B, Kallner A, Sjöberg LB, Pedersen BK: Supplementation with vitamins $\mathrm{C}$ and $\mathrm{E}$ inhibits the release of interleukin-6 from contracting human skeletal muscle. J Physiol 2004;558:633-645.

119 Pyne DB, West NP, Cox AJ, Cripps AW: Probiotics supplementation for athletes clinical and physiological effects. Eur J Sport Sci 2015;15:63-72. 